\title{
A Model of the Population of Fire Detection Equipment Based on the Geometry of the Building Stock
}

\author{
S. H. ELLWOOD and M. LYNCH \\ Gent Ltd \\ Waterside Road, Leicester LE5 1TN, UK
}

\begin{abstract}
The approach of studying a form of practical fire safety measure by considering the population of buildings to which it is applied has led to some interesting quantitative results. These include the distribution of the population of detection equipment and some indication of its possible effectiveness. on the basis of the model presented here the current population of detectors should be present at the start of about 4800 fire incidents, or $15 \%$ of the total, in non-domestic buildings in the UK. This then leads to some indication of the performance requirements both in terms of reliability and acceptable false alarm rate. Statistical studies of this nature ought therefore to be useful to designers and legislators when considering new products and standards. Further work should be done to improve the accuracy of some of the statistics used as inputs.
\end{abstract}

KEYWORDS Fire detection, effectiveness, population model.

\section{INTRODUCTION}

The work presented in this paper started as an attempt to model the market for fire detection and alarm equipment. Because of the complexity of the actual commercial market it was modelled in terms of the non-domestic building stock in the UK and the application of fire protection measures carried out in practice. The aim was then to discover what the market size was and how it was distributed between buildings of different type and size.

It was then realised that the information obtained for marketing purposes could be further refined and potentially applied to determine what the effectiveness of fire detection and alarm was in practice. The aim now is to determine if detectors are being used to best advantage, and where additional detectors could best be placed. This is in effect leading to a strategy for the application of detection and could be of value to legislators, manufacturers and end users. 
This paper describes the work done to date and presents some of the data obtained in surveys and calculations. The overall approach is different to the Delphi type models discussed by Harmathy [1] and Donegan [2]. These are based on average values of effects and interactions of fire safety measures, based on either a simple decision logic, or hierarchy of measures. Either method means that averages are spread widely and detail can be hard to determine. On the other hand complex overall strategies can be evaluated and compared. Ramachandran [3] uses a probabilistic approach based on a probability tree description of potential scenarios. The approach taken here is to study the application of one type of fire safety measure as though it were a population spread throughout a single country. The application of fire detection and alarm in non-domestic buildings in the UK is presented here, including some data on the occurrence of fires and non-fatal casualties superimposed on the population data. The following sections describe the three main steps in the analysis.

\section{ANALYSIS OF BUILDINGS/ROOMS}

The first stage is to determine the properties of the target population of buildings in which the detection and alarm equipment is installed. The non domestic buildings in the UK were divided into four broad categories:

- Accommodation, including: residential homes, hospitals, hotels and prisons.

- Leisure, including: sports centres, cinemas/theatres, churches, restaurants/pubs, Libraries/museums, historic.

- Services, including: transport, retail, education, health, other.

- Commercial, including: offices, warehouses and factories/plant.

The main categories are convenient as they are grouped approximately in relation to the behaviour of the occupants. This ranges from sleepers in accommodation to people very familiar with their surroundings in commercial. The analysis was carried out with separate data for each of the subcategories, but presented here mainly in the broad categories both for brevity and accuracy. Each building use category was divided into three size categories:

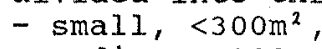

- medium, $>300$ and $<5000 \mathrm{~m}^{2}$, and

- large, >5000 $\mathrm{m}^{2}$

Data were obtained $[4,5$ used as basis] on the populations of non-domestic buildings and categorised according to the grouping above. Table 1 shows the populations (corrected for 1987), and the total areas.

To determine what fire protection is appropriate to apply to buildings of each type and size some idea of the geometry of each is required. For each of the 54 sub-categories by use and size a detailed example was evaluated (using a spread-sheet computer package). 
The example in table 2 showns the calculation for a medium sized residential rest home. The figures in the column marked 'variables' are all inputs to the computer which serve to describe an average building of the type. The figures in the column 'total areas' are the result of simple pre-programmed calculations. Several types of room were described:- rooms associated with corridors, corridors, (length assumed to be the square root of room area) stairs and lifts and other individual rooms which can be small storerooms, toilets or large factory or sales floors.

\begin{tabular}{cccr} 
Small & $\begin{array}{c}\text { Building size } \\
\text { Medium } \\
\left(<300 \mathrm{~m}^{2}\right)\end{array}$ & \multicolumn{3}{c}{$\begin{array}{c}\text { Large } \\
\left(>5000 \mathrm{~m}^{2}\right)\end{array}$} & Total \\
& & & \\
28490 & 26078 & 4458 & 59026 \\
$(1.42)$ & $(31.67)$ & $(56.42)$ & $(89.51)$ \\
193047 & 107807 & 2292 & 303146 \\
$(13.00)$ & $(102.93)$ & $(14.04)$ & $(129.97)$ \\
717596 & 123057 & 9715 & 850368 \\
$(68.94)$ & $(171.61)$ & $(74.97)$ & $(315.52)$ \\
205836 & 157906 & 17156 & 380898 \\
$(17.96)$ & $(133.63)$ & $(139.83)$ & $(291.42)$ \\
144969 & 414848 & 33621 & 1593438 \\
$101.32)$ & $(439.84)$ & $(285.26)$ & $(826.42)$
\end{tabular}

TABLE 1. 1987 population of non-domestic buildings in the UK categorised by use and size. Total areas are given below in brackets (given in $10^{6} \mathrm{~m}^{2}$ ).

Class: Medium Residential

Variables

Total

Corridortsmall rooms

$$
\left(<20 \mathrm{~m}^{2}\right)
$$

Corridortmedium rooms

$$
\left(<100 \mathrm{~m}^{2}\right)
$$

stairwells/lifts

Num. Rooms: 37

Ave. area: 20

Corr. Width: 2

Num. Rooms: 0

Ave area: 0

Corr. Width: 0

Num. S/lifts: 3

Ave. Num. floor: 2

Area/floor: 10

Number: 10

Individual rooms

Ave, area: 10

Individual rooms

Number: 2

Individual rooms

Ave, area: 110

Number: 3

Areas $/ \mathrm{m}^{2}$

Ave. area: 50

Subtotal: 740

Subtotal: 330.9

Subtotal: $\quad 0$

Subtotal: 0

Subtotal: $\quad 60$

Subtotal: 100

Subtotal: 220

Subtotal: 150

Total: 1600.9

Corridor length/m: $\quad 165.5$

TABLE 2. Example calculation of building geometry for medium sized residential building. 
The examples were then combined within each main category by type. They were then plotted to show the distribution of room sizes, by both building use and size (figures 1 and 2). These give few surprises, but give quantitative estimates on which to base further analysis. Totals indicated in the data are:

- Number of rooms: 15000000

- Corridor length: $18500000 \mathrm{~m}$

- (Number of stairs/lifts)*(number of floors): 3300000

It can be observed that the population of corridors is insignificant for small buildings compared with large ones, with the greater proportion in the accommodation sector and very few in leisure. Large rooms are infrequent in accommodation, but are important in service and particularly in commerce.

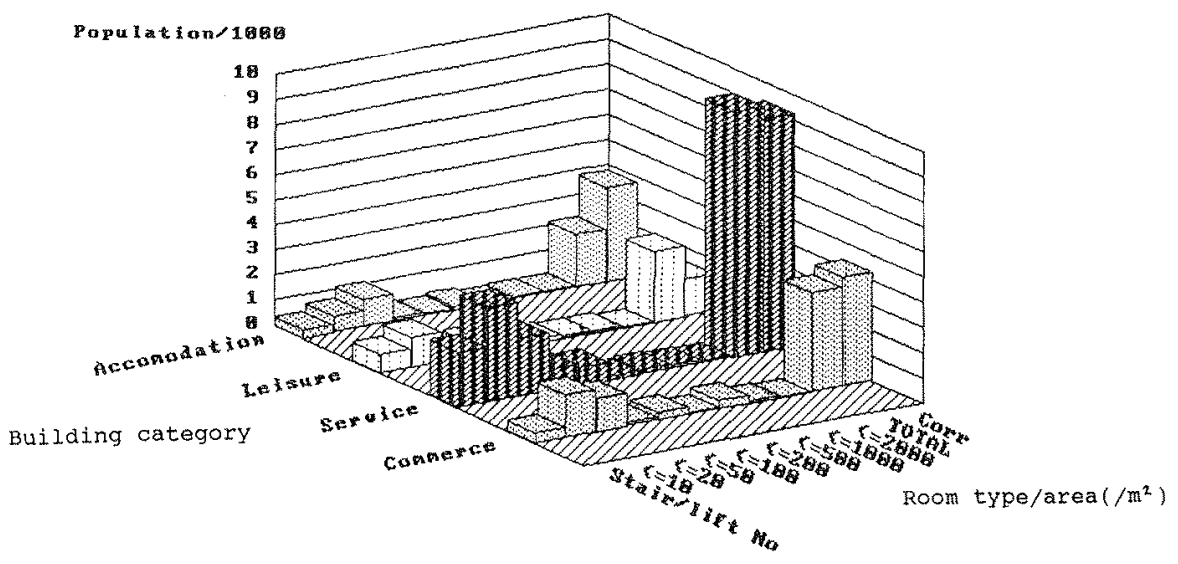

FIGURE 1. Distribution of room sizes in non-domestic buildings in UK, categorised by building use.

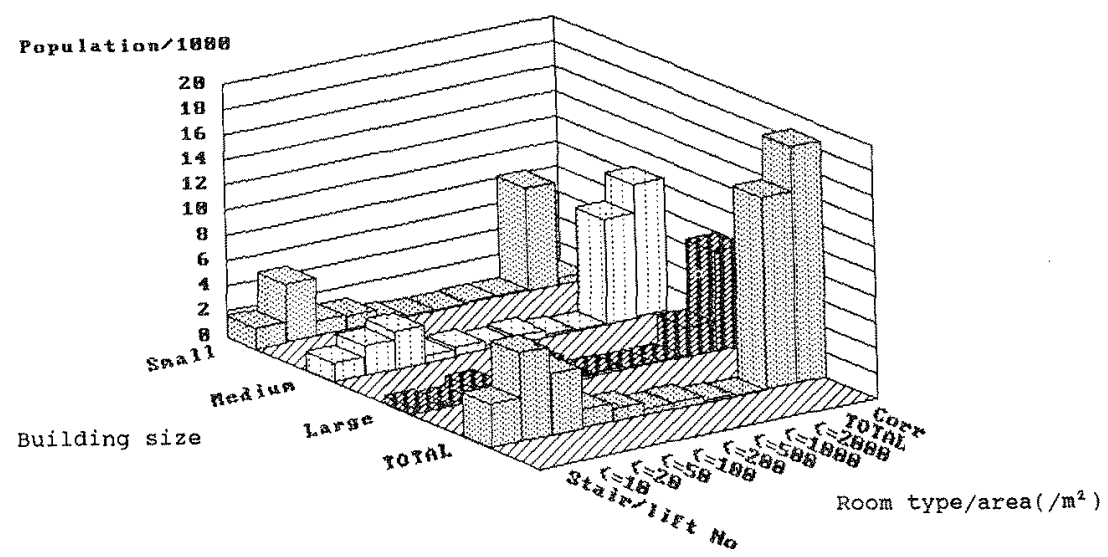

FIGURE 2. Distribution of room sizes in non-domestic buildings in UK, categorised by building size. 
The equipment items included in this paper are:

- point fire detectors,

- optical beam smoke detectors,

- manual call points,

- sounders/bells,

- fire alarm panels, quantified by total number of zones.

To determine what the actual coverage of fire detection and alarm equipment is in the buildings in this study, two further steps are required:

- The determination of the potential population of equipment if full coverage is made to the guidelines in the relevant code of practice [6]. Given that the geometry of example average buildings has been determined this can be calculated. Results of the totals for each category are given in table 3.

- The actual coverage which is existing in practice has then to be determined to allow the actual populations to be calculated. A small survey was carried out amongst fire prevention officers. They were selected as they proffessionally evaluate fire precautions in a wide range of premises. A total of 18 were interviewed, covering 8 counties in the UK. They were asked (for each sub-category) about the proportion of buildings that have manual or automatic fire detection and alarm systems, and about the average level of coverage. This information was combined with the data on potential population to give an estimate of actual population (table 3).

As a check on the results, end user prices and an average 12 year system life were assumed to obtain a market value of E54.7M, compared with a total of £60M from more conventional. market surveys [7]. It can be seen that the application of point detectors is approximately $14 \%$ of full coverage to the code of practice, with the greater density in the accommodation buildings. The coverage of manual systems is much greater at $68 \%$, most of the shortfall being in buildings less than $300 \mathrm{~m}^{2}$ where different regulations apply.

The need to include the geometry of buildings covered by detection was shown by the average coverage of detectors possible in medium sized residential properties at only $22 \mathrm{~m}^{2}$ per detector, compared with $42 \mathrm{~m}^{2}$ in medium sized warehouses. This is due to the greater number of individual rooms, corridors and stairs which need separate detection. The average size of buildings even within a size category varied greatly by building use type and was also an important consideration.

There is some under-estimate of the number of detectors potentially and actually installed, as the model includes only occupied floorspace and not roof and interfloor voids. This is a correction that needs to be made on a refinement of the model, but errors should not significantly affect the order of magnitude estimates and final ratios presented in this paper. 
The model assumed beam detectors would be installed if it was economic. This is not always common practice in the UK and results in an overestimate of the number of beams and slight underestimate in the number of point detectors.

Accommodation

point detectors

Beam detectors

Manual call points

Bell/sounders

Panel zones

Leisure

Point detectors

Beam detectors

Manual call points

Bell/sounders

Panel zones

Services

point detectors

Beam detectors

Manual call points

Bell/sounders

Panel zones

Commercial

Point detectors

Beam detectors

Manual call points

Bel1/sounders

Panel zones

Totals

Point detectors

Beam detectors

Manual call points

Bell/sounders

Panel zones

$\begin{array}{cccc}\text { Smal1 } & \begin{array}{c}\text { Building size } \\ \text { Medium } \\ \left(<300 \mathrm{~m}^{2}\right)\end{array} & \begin{array}{c}\text { Large } \\ \left(>5000 \mathrm{~m}^{2}\right)\end{array} & \text { Total } \\ & & & \\ 256(0) & 1540(1066) & 1326(573) & 3122(1639) \\ 0(0) & 0(0) & 0(0) & 0(0) \\ 59(7) & 285(285) & 314(310) & 658(602) \\ 71(8) & 342(342) & 376(372) & 789(722) \\ 83(7) & 159(131) & 129(93) & 371(231)\end{array}$

$\begin{array}{cc}1059(83) & 1846(141) \\ 0(0) & 89(9) \\ 71(19) & 799(556) \\ 84(22) & 959(667) \\ 264(63) & 677(258)\end{array}$

$\begin{array}{rr}82(8) & 2987(232) \\ 14(1) & 103(10) \\ 96(54) & 966(629) \\ 115(65) & 1158(754) \\ 48(16) & 989(337)\end{array}$

$\begin{array}{cccc}5063(0) & 3912(221) & 900(124) & 9875(345) \\ 0(0) & 92(2) & 56(11) & 148(13) \\ 1493(382) & 1009(922) & 281(258) & 2783(1562) \\ 1792(459) & 1211(1107) & 337(310) & 3340(1876) \\ 2196(281) & 814(394) & 182(98) & 3192(773)\end{array}$

$\begin{array}{cccc}1064(11) & 3588(413) & 835(281) & 5487(705) \\ 0(0) & 0(0) & 92(32) & 92(32) \\ 127(64) & 408(408) & 289(289) & 824(761) \\ 152(77) & 490(490) & 346(346) & 988(913) \\ 333(94) & 325(184) & 197(131) & 855(409)\end{array}$

$\begin{array}{cccc}7442(93) & 10886(1841) & 3143(985) & 21471(2919) \\ 0(0) & 181(11) & 162(45) & 343(56) \\ 1750(472) & 2501(2171) & 980(911) & 5231(3554) \\ 2099(557) & 3002(2606) & 1174(1093) & 6275(4256) \\ 2876(443) & 1975(957) & 556(338) & 5407(1748)\end{array}$

TABLE 3. Potential population of fire detection and alarm equipment in non-domestic buildings in the UK, if all buildings are fully covered to BS5839:part 1. Estimated actual population is given in brackets. (all figures/1000)

\section{DISTRIBUTION OF FIRES WITH RESPECT TO DETECTION}

The data on the distribution of fire detection can be compared with the distribution of fires and the extent of damage. For this purpose the data published by the UK Home office [8] was used. Unfortunately the data do not break down into building size, but are separated for different types of non-domestic 
building. With care the data could be matched with the categories used in this exercise. The published figures have to be used with some caution as they only relate to fire incidents attended by the fire brigade. Small incidents which are detected early by detectors or people, and dealt with quickly or fail to grow may be excluded.

Table 4 illustrates the relationship between the occurrence of fires and the building population. There is a large difference in the occurrence of fires in the different types of building. The ratio being $0.089 /$ building for accommodation and 0.014 /building for leisure premises. If the number of 'rooms' is considered by taking the sum of: the number of rooms, number of stairs/lifts and corridor length/50; the occurrence of fires per 'room' is then much more even, ranging from 0.0025 in accommodation to 0.0013 in services. In terms of overall floor area, fires per $10^{6} \mathrm{~m}^{2}$ range from 58.6 in accommodation to 32.93 in leisure. These figures compare well with those in Harmathy [1] who quotes 78.5 in hotels and health care, 25.6 in education and 24.5 in offices.

\begin{tabular}{|c|c|c|c|c|c|}
\hline & Accom. & Leisure & Services & comm. & Total \\
\hline Num. buildings & 59026 & 303146 & 850368 & 380898 & 1593438 \\
\hline Num. fires & 5249 & 4281 & 12784 & 9491 & 31805 \\
\hline Fires/building & 0.089 & 0.014 & 0.015 & 0.025 & 0.02 \\
\hline $\begin{array}{l}\text { Total 'rooms' in } \\
\text { buildings }(/ 1000)\end{array}$ & 2112 & 2786 & 9912 & 3911 & 18721 \\
\hline Fires/'room' & 0.0025 & 0.0015 & 0.0013 & 0.0024 & 0.0017 \\
\hline Area $/ 10^{6} \mathrm{~m}^{2}$ & 89.51 & 129.97 & 315.52 & 291.42 & 826.42 \\
\hline Fires $/ 10^{6} \mathrm{~m}^{2}$ & 58.64 & 32.93 & 40.42 & 32.57 & 38.48 \\
\hline $\begin{array}{l}\text { Non-fatal } \\
\text { casualties }\end{array}$ & 311 & 204 & 726 & 469 & 1710 \\
\hline Casualties/fire & 0.059 & 0.047 & 0.057 & 0.049 & 0.054 \\
\hline \multicolumn{6}{|l|}{ Fires confined to: } \\
\hline Item ignited & $\begin{array}{l}2819 \\
(54 \%)\end{array}$ & $\begin{array}{l}1332 \\
(31 \%)\end{array}$ & $\begin{array}{r}3901 \\
(31 \%)\end{array}$ & $\begin{array}{r}3673 \\
(40 \%)\end{array}$ & $\begin{array}{l}10526 \\
(35 \%)\end{array}$ \\
\hline Room & $\begin{array}{r}2179 \\
(42 \%)\end{array}$ & $\begin{array}{l}2411 \\
(56 \%)\end{array}$ & $\begin{array}{l}7441 \\
(59 \%)\end{array}$ & $\begin{array}{r}4919 \\
(52 \%)\end{array}$ & $\begin{array}{l}16947 \\
(56 \%)\end{array}$ \\
\hline Building & $\begin{array}{l}220 \\
(4 \%)\end{array}$ & $\begin{array}{r}485 \\
(11 \%)\end{array}$ & $\begin{array}{l}1217 \\
(9 \%)\end{array}$ & $\begin{array}{l}751 \\
(8 \%)\end{array}$ & $\begin{array}{l}2673 \\
(9 \%)\end{array}$ \\
\hline out of building & $(0.2 \%)^{9}$ & $\begin{array}{c}41 \\
(1 \%)\end{array}$ & $\begin{array}{r}76 \\
(0.6 \%)\end{array}$ & $\begin{array}{l}110 \\
(1 \%)\end{array}$ & $\begin{array}{l}236 \\
(1 \%)\end{array}$ \\
\hline
\end{tabular}

TABLE 4. OCcurrence of fires (1987) compared with the UK nondomestic building stock, and number of non-fatal casualties and extent of fires ( $\%$ figures for spread rounded separately). 
The average for non-domestic categories in Harmathy at 34.1 fires $/ 10^{6} \mathrm{~m}^{2}$ compares well with 38.48 fires $/ 10^{6} \mathrm{~m}^{2}$ in this work. It can therefore be observed that the occurrence of fires per building varies greatly by use type, but if the geometry of the buildings are considered then the variation is much reduced.

As an indicator of the relative severity of fire incidents table 4 also gives the figures for the number of casualties per fire which is evenly distributed by building type, even though it might be expected that there could be significantly more in the accommodation buildings. If the spread of fires is considered however it can be seen that there is a great difference between the extent of fires in accommodation where the majority are confined to the item first ignited, and the other categories where most reported incidents spread further into the room. This difference can also be seen in the proportion which extend beyond the room and the building. This difference in fire spread may then be consistent with the unexpected relative low difference in casualty rate; fires are actually more dangerous in accommodation buildings as smaller fires produce, on average, similar numbers of casualties.

The comparison between the occurrence of fires and the distribution of detectors is shown in table 5. The ratio between the actual and potential detector population is given here, and there can be seen to be a very large difference between the different building use categories with a coverage of 0.525 in accommodation buildings and as low as 0.035 in service buildings. The coverage in commercial buildings is relatively high at 0.128 . The very dense coverage of detection

\begin{tabular}{|c|c|c|c|c|c|}
\hline & Accom. & Leisure & Services & Comm. & Total \\
\hline Num. fires & 5249 & 4281 & 12784 & 9491 & 31805 \\
\hline $\begin{array}{l}\text { Actual detectors } \\
(/ 1000)\end{array}$ & 1639 & 232 & 345 & 705 & 2921 \\
\hline $\begin{array}{l}\text { Potential } \\
\text { detectors }(/ 1000)\end{array}$ & 3122 & 2987 & 9875 & 5487 & 21471 \\
\hline $\begin{array}{l}\text { Actual/potential } \\
\text { detectors }\end{array}$ & 0.525 & 0.078 & 0.035 & 0.128 & \\
\hline $\begin{array}{l}\text { Fires *act./pot. } \\
\text { detectors }\end{array}$ & 2756 & 333 & 447 & 1219 & 4755 \\
\hline $\begin{array}{l}\text { Fires/potential } \\
\text { detectors }\end{array}$ & 0.0017 & 0.0014 & 0.001 & 0.0017 & \\
\hline $\begin{array}{l}\text { Potential } \\
\text { detectors/fires }\end{array}$ & 595 & 697 & 772 & 578 & \\
\hline
\end{tabular}

TABLE 5. Occurrence of fires compared with potential and actual fire detectors in non-domestic buildings, 1987. 
is one factor potentially reducing the relative spread of fires in the accommodation sector. This has to be linked with other passive fire protection means and the actions of occupants and staff members.

The product of the coverage ratio and the number of fires in each category gives a measure of the number of fires which are detected, or capable of being detected by automatic detectors in a year. The total is 4755 for 1987 . The published statistics do not indicate the origin of the alarm, ie whether a person or fire detector first detected a fire, but the number of false calls from systems is. In 1985 the total of calls due to 'apparatus faults' was 54000 which means that the figure for alarms obtained here is consistent with the ratio of approximately 15 [9] that is often reported between false and true alarms for automatic systems. There is a wide variation in building type from which these calls are likely to occur. Table 5 shows a figure of 2756 for accommodation and only 333 for leisure buildings. The number of actual calls from detectors will be lower because of detection fxom people present, and increased by the chance of a detector remote from a fire operating within an unoccupied building.

The ratio of the number of fires to the number of potential detectors gives a measure of the probability of a fire at a detector in a year in each of the building types. The spread is very small with average of 0.0015 . The reciprocal gives the average number of years between true fires for a detector as 675. If there is a requirement for the ratio of false to true alarms to fall to $1: 1$ then this quantifies the aim. More detailed work based on this approach would be required to determine more accurate figures. In particular what would be useful is a study to determine where extra fire detection could best be added, and what benefit this would bring.

It is also possible to estimate how many fires might not be detected if a fault occurs. Figures for the reliabilty of conventional and advanced systems are given by Appleby and Ellwood [10]. On average between 96 and 23 incidents could be affected depending on the level of technology. Consideration of system designs and standards should relate to reliability figures which can be directly translated into the impact on safety, rather than be based on more arbitrary factors.

\section{CONCLUSIONS}

This paper describes an approach to the analysis of fire detection, which considers the overall population distribution of systems in comparison with that of the building stock. Estimates of the numbers of detectors and other equipment actually installed and potentially installed can be made.

The density of detectors can be compared with the occurrence and extent of fires in different categories of building and some indication can be obtained of their effectiveness. Further work could be undertaken to better quantify this aspect 
and lead to better understanding of the trade offs with other fire protection measures. However, this paper includes values which can be used as a basis for quantitative requirements for reliability in terms of false alarm rate and availability. These should be used in product and system design and development stages, and also in considering standards requirements.

Finally, there is no reason why this type of method should not be applied to other fire safety means. A knowledge of the overall distribution of equipment or measures can be used to determine where extra effort is best placed to improve life and property protection.

\section{REFERENCES}

1. Harmathy, T. Z., "A Decision Logic for Trading between Fire Safety Measures", Fire and Materials, 10, pp 1-10, 1989.

2. Donegan. H. A., Shields, T. J., and Silcock, G. W., "A Mathematical strategy to Relate Fire Safety Evaluation and Fire Safety Policy Formation for Buildings", in proceedings of Second International Symposium on Fire Safety Science, pp 433-441, Hemisphere, 1989.

3. Ramachandran, G., "Trade-offs between Different Fire Safety Measures: Probabilistic Evaluation", Fire Surveyor,19, Number 2, pp 4-13, 1990.

4. Herring, R., Energy Use and Efficiency within UK Commercial and Public Biuldings up to year 2000 , HMSO, 1985.

5. Langley, F. K., Energy Use and Efficiency within UK Manufacturing Industry, HMSO, 1985.

6. BSI, BS5839:part1:1988, Code of Practice for System Design Installation and Servicing.

7. Ellwood, S.H., "Extension of UK FD\&A Market Model Based on Building Geometry", Gent Ltd internal report, 1989.

8. Home office, Fire Statistics United Kingdom 1987, Home office Statistical Department, 1989.

9. Guettinger, $\mathrm{H}$. and scheidweiller, H., "New ways towards and Solutions to the False Alarm Problem", in Proceedings of the second International symposium on Fire safety Science, pp 583-590, Hemisphere, 1989.

10. Appleby, D. and Ellwood, S. H., "A Fire Detection system Using Distributed Processing", pp 101-116, AUBE ' 89 proceedings. 